\title{
La agroecología, alternativa de desarrollo para el modelo
}

agrícola predominante

\section{La propuesta del nuevo paradigma apunta a que sí es posible la producción sustentable, demostrada a través de diferentes experiencias en Latinoamérica y en otros continentes.}

Beatriz E. Castaño R.

El modelo de agricultura que predomina hoy, caracterizado por el uso intensivo de combustibles fósiles, los agroquímicos, la mecanización agrícola y las variedades mejoradas ha demostrado una alta productividad. No obstante, este modelo ha beneficiado principalmente a los países industrializados y sigue sin tener en cuenta los impactos ambientales, sociales y económicos generados en las comunidades campesinas e indígenas de los países en vías de desarrollo, que contribuyen en un alto porcentaje a la seguridad alimentaria de las poblaciones urbanas.

El desarrollo de tecnologías que se dio en el siglo XX en las potencias económicas mundiales, con la inversión en investigación científica para la agricultura, logró producciones agrícolas sin precedentes. Es así, como tomó aproximadamente mil años para que la producción de los cultivos de trigo en el Reino Unido aumentara de 0.5 a 2.0 toneladas por hectárea, y en solo 40 años pasara de 2.0 a 6.0 (Hazell,2002).

Sin embargo, para la mitad de los años 60, aunque existían cantidades abundantes de arroz y trigo en los países industrializados, el hambre y la malnutrición se expandían en los más pobres, especialmente de Asia y África. En India murieron miles de personas, lo que llevó a pensar a algunos Gobiernos en invertir en sistemas de producción de alimentos para los países que se denominaron del tercer mundo que, desde su independencia habían aumentado sus poblaciones a niveles extremadamente altos. 
Fue entonces cuando fundaciones privadas de los Estados Unidos tomaron el liderazgo para establecer en esas regiones un sistema internacional de investigaciones en agricultura, con el fin de transferir y adaptar los adelantos obtenidos en las potencias mundiales. Y, a finales de los años 60, una vez importado el "mismo modelo" de uso de semillas mejoradas, fertilizantes de síntesis química, mecanización, irrigación, entre otros, se dan los mismos resultados en la producción obtenidos en los países generadores de tales tecnologías.

\section{La Revolución Verde}

En Latinoamérica como en Asia y, en menor medida en África, empiezan las producciones inigualables de arroz y trigo, cultivos con los que también se dio inicio a la transferencia de tecnologías. A este fenómeno de crecimiento en la agricultura se le denominó "Revolución Verde".

\section{Aunque para 1970 dicho} fenómeno duplicó la producción de arroz y trigo para los productores de los países asiáticos y latinoamericanos, también se incrementaron las necesidades de insumos, materiales y equipos para mantener las producciones altamente exigentes. Los nuevos ingresos también dieron lugar a una demanda de mayores bienes y servicios, lo que generó en muchos de los países en vías de desarrollo, la creación de una nueva economía rural basada en la no-agricultura.

Incrementar la pila de alimentos no ha aliviado el problema de hambre en el mundo, como bien se puede verificar, porque no se han distribuido en forma equitativa. De haberlo hecho, desde 1997 alcanzarían para alimentar a todos los individuos de nuestra especie y se evitaría la muerte por hambre de cerca de 800 millones de adultos y cinco millones de niños al año (Pengue, 2008).

Por supuesto, existen otras variables en este problema relacionadas con las decisiones políticas en torno a la distribución de los recursos; pero solo quiero referirme al modelo agrícola predominante y a los aspectos que lo hacen inconsistente.
Aunque en varios países el precio de los alimentos bajó, permitiendo un incremento en el acceso, un mayor consumo de calorías y una dieta más diversificada -beneficios que algunos críticos le atribuyen a la reducción de la pobreza, en Asia especialmente-, la Revolución Verde trajo consigo una serie de problemas que una década después comenzaron a poner en duda su sustentabilidad.

\section{Aumento de la pobreza}

Como está demostrado en un sinnúmero de experiencias de todos los países en vías de desarrollo, la Revolución Verde produjo también una degradación ambiental; inequidad en la distribución de los ingresos y de los activos; pérdida de la capacidad productiva de los suelos y de la biodiversidad; erosión genética y dependencia creciente de insumos provenientes de combustibles fósiles; erosión cultural y contribución al calentamiento global. En resumen, empeoramiento de la pobreza.

Una de las mayores críticas a la Revolución Verde es que benefició a los grandes productores, mientras dejó a un lado los pequeños y medianos, quienes durante miles de años desarrollaron sus propias formas de agricultura, para garantizar su seguridad alimentaria. Los grandes productores tuvieron acceso a las nuevas tecnologías lo que les permitió aumentar sus producciones, incrementar sus rentas y crear una competencia desigual de precios con los pequeños agricultores, quienes se vieron forzados a salir de sus tierras. La Revolución Verde también incentivó la mecanización innecesaria causando una disminución en el precio de los jornales y el desempleo.

Los campesinos, en su gran mayoría analfabetos, comenzaron a adoptar las modernas tecnologías de la Revolución Verde, sin una adecuada capacitación y en ausencia de regulaciones políticas que contemplaran la calidad del agua y el manejo de los suelos tropicales, entre otros aspectos. Vacíos que contribuyeron a generar contaminación y envenenamiento de la vida silvestre, sumados a los peligros de los pesticidas, sobre los cuales no recibieron orientación ninguna. 
Además de los resultados equívocos que se han podido sistematizar de la Revolución Verde, en los países en vías de desarrollo, fueron sus promotores quienes decidieron invertir en el desarrollo de biotecnologías en los años setentas, tales como los organismos genéticamente modificados (OGM).

Profundizar en los OGM tomaría un capítulo completo, sin embargo, vale la pena observar los resultados existentes sobre quiénes han sido los más afectados con los impactos ambientales, registrados con los cruces horizontales, como la aparición de las supermalezas en Argentina; tal situación genera gran desconcierto y temor.

Más aún, cuando se analiza el marcado interés de patentes y dominio de las semillas, base de la alimentación de la humanidad. Entonces, es válido plantear alternativas diferentes a los modelos agrícolas impuestos desde otras latitudes, que demuestran una y otra vez ser insustentables para la realidad de nuestros países tropicales.

\section{La agroecología, una buena alternativa}

Ante el panorama descrito, la Agroecología surge en Latinoamérica como una respuesta para encarar la crisis ecológica, además de los problemas sociales y medioambientales generados por esta, a partir del manejo sostenible de los recursos naturales y el acceso igualitario a ellos (Altieri, 1999).

Esta ciencia que trata de construir el desarrollo entendiendo la coevolución social y ecológica de los sistemas; que busca una menor dependencia de los insumos externos; que toma en cuenta los procesos de autogestión y participación comunitaria; el uso de recursos renovables locales; el mantenimiento de la capacidad productiva; el respeto a la diversidad cultural; el uso de la experiencia y conocimiento locales; el mejoramiento de la diversidad biológica; y, la atención a los mercados locales y externos (Gliesman 2002, citado por Morales, 2008), entre otros aspectos, empieza a convertirse en una opción de desarrollo sustentable para los países del trópico. Es necesario anotar, que el ideal de sustentabilidad inicia su proceso en las últimas décadas, especialmente después de la Conferencia de Estocolmo, en 1972 (Caporal \& Morales, s.f.).

En las experiencias que comienzan a mostrar viabilidad económica, social, ambiental y cultural de propuestas agroecológicas en Latinoamérica y que han surgido desde las necesidades mismas de las comunidades, confluyen diferentes actores sociales, entre los que se cuentan campesinos, indígenas, consumidores ecologistas, ONGs, universidades, empresas y distintos niveles de gobierno (Morales, 2008).

De ahí que en la actualidad, ya se cuenten más de 400 mil pequeños productores, indígenas y campesinos en Latinoamérica, certificados como orgánicos y aportantes del $24.2 \%$ de la superficie agrícola mundial, dedicada a la agricultura orgánica (Morales, 2008).

"Los campesinos e indígenas en Latinoamérica constituyen un importante sector que concentra el $45 \%$ de la población mundial y dispone del $33 \%$ de la superficie cultivable; además de representar el $26 \%$ de la población económicamente activa .Su importancia se incrementa al considerar que además de abastecerse, se encargan del $40 \%$ de la producción para el mercado interno, y del $35 \%$ de los cultivos de exportación. Los campesinos latinoamericanos producen el $77 \%$ del fríol; $51 \%$ del maíz; y, el $61 \%$ de las papas de la región. En Bolivia aportan el $80 \%$ de la producción nacional; en Perú el 55\%; en México el $47 \%$; en Brasil el $40 \%$; y, en Chile el 38\%" (Kay, 1994. Citado por Caporal y Morales, s.f.).

"Actualmente en Latinoamérica, señalan

Altieri \& Nicholls (2001), hay miles de casos de productores rurales que, en asociación con ONGs y otras organizaciones, promueven sistemas agrícolas y conservan los recursos, en torno a altos rendimientos y en cumplimiento de los criterios de la Agroecología -aumentos del 50 al 100\% en la producción, son bastante comunes en la mayoría de los métodos agroecológicos. En ocasiones los rendimientos 
de cultivos que constituyen el sustento de los pobres -arroz, fríjol, maíz, yuca, papa, cebada, entre otros productos- se han multiplicado gracias al trabajo y conocimiento locales, más que a la compra de insumos costosos y optando por capitalizar la intensificación de la mano de obra y las sinergias. Los mismos autores concluyen que más allá de los rendimientos, la importancia radica en que es posible aumentar de manera significativa la producción, diversificando los sistemas agrícolas y usando al máximo los recursos disponibles". (Caporal \& Morales, s.f.)

\section{El país de cara a la problemática}

Colombia no es la excepción y son los campesinos, indígenas y afrodescendientes quienes, a pesar de representar las minorías en el país, contribuyen con más del $50 \%$ de los alimentos para la canasta básica en los hogares colombianos. Ellos, a pesar de las adversidades, siguen sobreviviendo y mostrando formas alternativas para producir, mediante sistemas agroecológicos.

Queda entonces la propuesta del nuevo paradigma que apunta a que sí es posible la producción sustentable, demostrada a través de diferentes experiencias en Latinoamérica y en otros continentes.

Cabría preguntarse ¿cuáles serían los resultados si la Agroecología tuviese la inversión de capital realizada para la Revolución Verde o la que registra en la actualidad la revolución biotecnológica? No se sabe, pero lo que sí es cierto, es que los contradictores de la propuesta agroecológica no han tomado mucho en cuenta la cantidad y la forma como se han invertido los capitales en ambas propuestas.

\section{Los retos}

Desde el rol de la universidad y específicamente desde los programas en Agroecología tenemos varios retos. Quiero mencionar tres que considero muy importantes.

El primero, formar profesionales con sólidos valores éticos, responsabilidad social y empresarial, compromiso ambiental y con bases técnicas para entender los procesos agroecológicos, de una manera integral y no atomista, como se ha hecho tradicionalmente.

Un segundo reto, representa seguir construyendo las bases científicas de la Agroecología. Estas bases no las podemos construir solos, sino en conjunto con los saberes de los campesinos, indígenas, afrodescendientes y demás actores y ciencias que le aportan a esta propuesta de desarrollo sustentable.

Y, un tercer reto, es cómo propender por un consumo responsable que permita ampliar y consolidar los mercados solidarios y el comercio justo, para generar las bases económicas orientadas a consolidar el desarrollo sustentable que queremos.

\section{Referencias}

[1] Altieri, M. (1999). Agroecología, as bases científicas da agricultura alternativa. PTA/FASE. Pág 10.

[2] Altieri, M. \& Nicholls, C (2008). Agroecología: principios y estrategias para una agricultura sustentable en la América Latina del Siglo XXI. Recuperado el 21 de septiembre de 2008, de www.agroeco.org. http:// agroeco.org/doc/agroecologia-principios.doc.

[3] Caporal, F. \& Morales, J. s.f. La Agroecología desde Latinoamérica: avances y perspectivas. pág 4. [4] Hazel, B. R. (2002). Green Revolution, Curse or blessing?. International Food Policy Research Institute, IFPRI. 2 - 4.

[5] Morales, J. (2008). Los movimientos sociales rurales y la agroecología: avanzando hacia la sustentabilidad rural. Primer seminario internacional de agroecología, bases para el desarrollo sustentable. Villavicencio, Colombia.

[6] Pengue, W. (2008). Comentarios sobre Economía Ecológica y alguno que otro conflicto ecológico distributivo. GEPAMA. pág 14.

Beatriz E. Castaño Ramírez. Directora Programa de Ingeniería Agroecológica, Corporación Universitaria Minuto de Dios UNIMINUTO. 